\title{
Renunciantes de Direitos? A Problemática do Enfrentamento Público da Violência Contra a Mulher: o Caso da Delegacia da Mulher
}

ELAINE REIS BRANDÃO •

\section{RESUMO}

O artigo discute a "suspensão" da queixa policial na Delegacia Especializada de Atendimento à Mulher (DEAM), procedimento usual até a Lei no 9.099/ 95, que instituiu os Juizados Especiais Criminais e o novo encaminhamento jurídico para as denúncias de atos violentos contra as mulheres. Trata-se de um estudo etnográfico, realizado entre 1995-1996, no qual se observou a dinâmica de atendimento policial em uma DEAM do estado do Rio de Janeiro, tendo sido também entrevistadas 32 mulheres que recorriam à DEAM em momento posterior à denúncia, para prestarem depoimentos ou solicitarem a "retirada" da queixa. Dentre os resultados, abordam-se as especificidades da demanda feminina à polícia, na qual os delitos denunciados estão subsumidos a um conjunto mais amplo de queixas referidas às "perturbações" masculinas à ordem familiar.

Palavras-chave: Gênero; violência contra a mulher; delegacia da mulher; família.

Recebido em: 04/09/2006.

Aprovado em: 23/10/2006. 


\section{Introdução}

A problemática que os resultados da pesquisa aqui tratada levantam permanece no centro do debate sobre o enfrentamento público da violência contra a mulher. Considerar a lógica cultural que ordena a visão de mundo dos atores sociais envolvidos nos episódios de violência conjugal denunciados à polícia, bem como as práticas sociais dos agentes institucionais responsáveis pelo encaminhamento legal de tais denúncias são aspectos de suma importância para a compreensão das distintas respostas à institucionalização desses conflitos. A institucionalização de respostas públicas ao problema da violência contra a mulher se pauta pela perspectiva da cidadania e dos direitos humanos, expressa no plano normativo-legal, que por sua vez orienta a formulação de políticas públicas na direção da defesa dos direitos da mulher. Tal orientação se choca com o recorrente apelo à ordem familiar, como instância hierárquica e de subordinação da mulher, pelos atores institucionais envolvidos na atenção às vítimas, seja na polícia ou nas instâncias jurídicas subseqüentes. Adesqualificação da violência contra a mulher pela instituição policial ou jurídica, no sentido de minimizar seus efeitos, impulsionando a interrupção dos procedimentos legais, por meio de "suspensão" da queixa (BRANDÃO, 1997 e 1998) ou arquivamento de inquéritos (CARRARA et al., 2002), no período anterior à Lei $n^{\circ} 9.099 / 95,{ }^{1}$ ou do favorecimento da renúncia ao direito de representação contra o acusado nas audiências de conciliação dos Juizados Especiais Criminais (DEBERT, 2002; DEBERT, BERALDO OLIVEIRA, 2005; AZEVEDO, 2005) permanecem sendo alguns obstáculos à efetivação de direitos assegurados às mulheres. ${ }^{2}$

A maioria das mulheres que acionam a Delegacia Especializada de Atendimento à Mulher (DEAM) descarta a punição legal dos parceiros acusados. $\mathrm{O}$ artigo discute a solicitação feminina para interrupção dos trâmites legais desencadeados com a denúncia policial, abordando a lógica cultural que preside a "suspensão" da queixa policial em uma DEAM do estado do Rio de Janeiro. Embora ilegal, tal procedimento era corrente no cotidiano do atendimento policial no período anterior à Lei $n^{\circ} 9.099 / 95$, a qual redefine o fluxo das demandas femininas que chegam à DEAM, encaminhando-as para os Juizados Especiais Criminais. Àquela época, em geral, em torno de 70\% dos registros de ocorrência efetivados anualmente nas delegacias terminavam suspensos (BRANDÃO, 1997, 1998; CARRARA et al., 2002; SANTOS, 1996, s/d; IZUMINO, 2004).

Aborda-se a "suspensão" da queixa policial sob duas perspectivas: o contexto institucional que a engendra, através do atendimento policial às vítimas 
e o universo sociocultural da maioria das mulheres que acionam a DEAM, recortadas em seu prisma de gênero (HEILBORN, 1993). A perspectiva de compreender a suspensão da queixa policial como dispositivo institucional engendrado no âmbito da relação policial-vítima permite relativizar a percepção, bastante difundida no senso comum, que a considera uma manifestação unilateral da mulher - decorrente de sua "submissão", "não-consciência dos direitos de cidadania", "dependência financeira", "falta de informação" ou "medo".

Operou-se o deslocamento do enfoque da relação conjugal violenta para a trama social que engendra os padrões de moralidade vigentes no grupo em estudo, apoiando-se nas contribuições de Duarte (1986), Salem (1981) e Sarti $(1989,1996)$, os quais ressaltam a relevância da instância familiar como locus privilegiado da construção da pessoa nesse universo cultural. Há nas classes trabalhadoras urbanas uma forte demarcação dos papéis conjugais, valorados diferencial e hierarquicamente, segundo os padrões de moralidade das redes de parentesco e localidade. Tais padrões nos remetem fundamentalmente ao plano das qualidades morais, mais intrínsecas à pessoa, "axiada em torno de categorias tais como vontade, obrigação, juízo, responsabilidade e honra" (DUARTE, 1986, p. 157). No contexto desse universo cultural, busca-se entender o enfrentamento feminino da violência conjugal.

\section{Estratégias metodológicas}

Trata-se de estudo etnográfico desenvolvido em uma DEAM do estado do Rio de Janeiro, cujo trabalho de campo ocorreu entre maio de 1995 e maio de 1996. Três estratégias metodológicas foram utilizadas para coletar os dados: a observação do atendimento policial cotidiano, principalmente dos interrogatórios que constituíam a fase preliminar de investigação, recomendando a instauração do inquérito ou a "suspensão" do registro; a consulta aos registros "suspensos" do ano de 1995 e entrevistas em profundidade com 32 mulheres que retornaram à DEAM, espontaneamente ou convocadas pela polícia, solicitando "retirar" a queixa registrada ou acatando tal sugestão policial. ${ }^{3}$ As entrevistas ocorreram em sala reservada da delegacia, tendo sido gravadas com consentimento das mulheres. A prioridade na escolha das informantes obedeceu aos critérios de ocorrência de agressão física no interior de um vínculo afetivo-sexual. Neste sentido, a investigação esteve circunscrita à suspensão de queixas de ameaça e lesão corporal - classificadas como "leves" pelo Instituto Médico Legal, o que caracteriza a maioria das ocorrências na DEAM. Das 32 
entrevistadas, sete haviam feito registro de ameaça, mas foram incorporadas porque relataram agressões físicas sofridas durante a convivência conjugal.

Assim, as entrevistas foram realizadas em momento posterior ao registro da queixa, permitindo captar a reconstrução do conflito ocorrido e das circunstâncias que geraram a denúncia, bem como ter acesso ao período entre a denúncia à DEAM e o retorno da mulher para se manifestar sobre o encaminhamento desejado. Sem dúvida, abordar tais mulheres alguns dias ou meses após a queixa redimensiona o contexto da denúncia, permitindo o acesso a reinterpretações da violência ocorrida. $\mathrm{O}$ roteiro de entrevista abordou os seguintes tópicos: identificação; contexto sociofamiliar de origem; relações conjugais anteriores; contexto sociofamiliar atual; conflito que motivou a denúncia; a queixa policial; suas conseqüências e, por fim, sua suspensão.

$\mathrm{Na}$ análise dos resultados, aborda-se a especificidade da demanda feminina que chega à DEAM e a dinâmica do atendimento policial, no qual a "suspensão" da queixa é, ao mesmo tempo, censurada e favorecida. Em seguida, destaca-se a apreensão feminina do fenômeno. Demonstra-se que, ao acionar a DEAM, as mulheres estabelecem um modo peculiar de utilização do aparato policial, permitindo compreender a "suspensão" da queixa inserida num conjunto de recursos que elas mobilizam para gerenciar a crise conjugal e familiar que subjaz o delito denunciado.

Na ocasião da pesquisa, em 1995-1996, não havia regulação pela CONEP dos procedimentos éticos relativos às investigações na área da saúde.

\section{Resultados}

\section{As mulheres na DEAM}

Um traço recorrente da demanda feminina à DEAM tem sido seu caráter multifacetado, extrapolando freqüentemente as atribuições policiais tout court. A percepção da DEAM como uma instância "que defende os interesses da mulher" permite múltiplas interpretações do que sejam os "interesses" ou os "direitos" da mulher, descortinando uma variedade de questões relacionadas à conjugalidade, às relações de vizinhança, de trabalho, à convivência entre gerações, à moralidade, à família, à moradia etc. Há que se considerar, conforme vários trabalhos têm revelado (KANT DE LIMA, 1994; MOTA, 1995; MUNIZ, 1996; SOARES et al., 1996; SOARES, 1996), que a agência policial adquire 
especial importância junto às classes trabalhadoras, as quais tradicionalmente a reconhecem e a legitimam como uma instância de resolução de conflitos, a despeito de sua dimensão repressiva.

Nem sempre a demanda feminina à DEAM está relacionada à ocorrência de violência tal qual prevista em lei. Muitas mulheres buscam o plantão apenas para informações sobre os seus "direitos" (custódia de filhos, partilha de bens, recebimento de dívida, suspeita de sedução, danificação de objetos domésticos) ou sobre algum atendimento especializado de que necessitam. Algumas recorrem à polícia para se aconselharem sobre como devem agir com a filha adolescente que saiu de casa ("fugiu com o namorado") ou que perdeu a virgindade com "um velho nojento, um safado de 64 anos". Mesmo quando as queixas contemplam atos violentos previstos na legislação penal, nem sempre as vítimas estão decididas a formalizá-las em um registro de ocorrência. A ambigüidade no tocante à punição legal do acusado constitui um traço marcante das queixas femininas trazidas à DEAM.

De maneira geral, as informantes justificam sua denúncia pelo receio de novas agressões ou ameaças, pelo imperativo de ter que fazer alguma coisa, pela disputa da casa, terreno ou eletrodomésticos durante o processo de separação conjugal, para "ferrar" o parceiro ou "botar pra quebrar", para "procurar meus direitos", "tomar atitude" ou "mostrar para ele que eu não sou igual àquelas outras". O tempo transcorrido entre a agressão física ou ameaça sofrida e a decisão feminina de denunciar é variável, sugerindo reações bem diferentes e denotando a complexidade do processo vivido pelas mulheres (GROSSI, 1998).

Alguns aspectos podem abalar uma certa tolerância feminina à violência marital. Há um determinado padrão ou conjunto de regras que se rompe com o fato delatado. Certos aspectos do ato denunciado podem ser captados como agravantes, impulsionando a mulher a recorrer à DEAM para fazer o registro:

- O fato de a agressão ter ocorrido em espaço público, como ressalta uma depoente: "Mas dessa vez, eu tive dois motivos. Primeiro, todo mundo viu. Segundo, eu tive uma perfuração no tímpano. Ficou uma lesão". No laudo do IML, os peritos consideraram a lesão de caráter reversível (e de natureza "leve").

- Ter deixado "marca" no corpo da vítima, o que remete não só à visibilidade pública das agressões físicas sofridas, mas à concepção 
de corpo e pessoa evidenciada por Duarte (1986) em tais segmentos sociais. Há uma escala de gravidade que classifica as agressões cujas lesões são visíveis e as que não chegam a deixar marcas, sendo o "tirar sangue" uma medida de avaliação importante. "Bater na cara" ou na cabeça recebem ênfase especial, por sua repercussão eminentemente "moral". No contexto da denúncia, tais marcas podem oferecer "provas" contra os acusados mediante o encaminhamento das vítimas à "perícia", o que pode ser um aspecto valorizado conforme os objetivos subjacentes ao recurso feminino à polícia.

- A vítima ter sofrido pressão de familiares, empregadores ou advogados para fazer a denúncia. Este aspecto, tomado como incentivo no momento da denúncia, reaparece na ocasião da suspensão, quando a queixa é reconstruída, com conotação inversa: como justificativa para a tensão que antecede o registro (referências ao "nervoso", "revolta", "raiva", "dúvida"). A denúncia passa a ser minimizada por ter sido submetida à interferência de terceiros.

- A responsabilidade da maternidade, no sentido de preservar os filhos em situações de risco, instabilidade ou sua própria vida. A preeminência do vínculo familiar encontra-se na raiz da representação que a mulher tem de si como pessoa.

Em síntese, ao se dirigirem à DEAM com "muita raiva" porque o companheiro está "abusado demais", com "vergonha", "magoada" ou até mesmo com medo de a polícia prendê-las, tais mulheres evidenciam o quanto é difícil tomar a decisão de registrar a queixa. A denúncia do parceiro à polícia significa certo rompimento de sua parte com a reciprocidade familiar, embora como resposta às rupturas causadas pelos homens nesse contexto.

Dentre as mulheres que se dirigem à DEAM convictas da denúncia e da necessidade de punição aos agressores, poucas se manifestam favoráveis à prisão do acusado. A maioria afirma querer somente "dar um susto", "uma prensinha nele", "um castigo", "chamar para conversar", "que ele me dê sossego", "que ele me deixe em paz", "que ele saia de casa" ou permanecer na própria casa, já que "ele quer que eu saia de casa".

A ida à DEAM envolve a esperança "dele melhorar", "dele tomar vergonha na cara", de "resolver alguma coisa" ou de propiciar uma ocasião para amedrontar o parceiro quanto às possíveis implicações de uma próxima 
agressão, pelo fato de ele já estar envolvido como suspeito em uma ocorrência. Assim, imensas expectativas são depositadas no recurso à DEAM, na possibilidade de a intervenção policial conter o acusado.

Tais expectativas são consideradas vagas pela(o)s policiais, que encontram dificuldades em transmutá-las para os termos penais previstos. Correspondem a um universo completamente distinto daquele pressuposto pelo ordenamento jurídico formal, porque expressam uma visão de mundo totalizante. Ao reivindicarem determinadas medidas "corretivas" contra os parceiros, as mulheres não buscam uma punição específica àquele delito denunciado, mas a restauração de toda uma ordem que confere sentido não só àquela relação, mas à sua existência social.

Alheias à ordenação jurídica que rege a DEAM, as mulheres estranham o universo da burocracia e não distinguem a pertinência legal dos conflitos que explicitam em suas queixas: "Pensei que dava a queixa e depois saía a separação", expressa decepcionada uma mulher à policial que a atendia. Contudo, a interação que estabelecem com os policiais na DEAM tem gerado, em certos momentos, uma participação ativa das vítimas na construção da queixa a ser registrada, indicando que a atividade de triagem e classificação das queixas nos respectivos termos legais não tem sido tarefa exclusivamente policial.

A capacidade de convencimento da mulher ao relatar a violência sofrida não pode ser desprezada, ao explicitar elementos que realcem seu lugar de vítima, contrastando-os com os atributos depreciativos do suspeito. Conforme as circunstâncias de sua ida à DEAM e o objetivo que busca alcançar, tanto pode fornecer informações que agravem a situação do acusado, quanto omitir outras, orientando, em parte, os termos do registro. Em casos nos quais percebe a não-disponibilidade policial para registrar o fato que a preocupa (nem sempre contemplado pelo Código Penal), a mulher pode lançar mão de determinados recursos para adaptar estrategicamente sua queixa aos preceitos legais - por exemplo, alegando ter recebido uma ameaça.

\section{A ruptura de um ideal de reciprocidade}

Quanto às razões que as levaram a procurar a polícia, o aspecto principal é a dificuldade de atualização de um regime ideal familiar. Se o ideal não se cumpre, isso se deve, na ótica feminina, mais às "perturbações" causadas pelo companheiro, do que à determinada agressão física ou ameaça sofridas. A 
exemplo do uso mais estrito que Duarte (1986) faz da noção de "perturbação físico-moral", num sentido mais amplo, aqui também as "perturbações" masculinas assumem dimensões a um só tempo físicas e morais, apresentando-se como um conjunto de atitudes masculinas desaprovadas pelas mulheres (não-trabalho, uso exagerado de bebida alcoólica ou drogas, maus-tratos, ter outras mulheres), que impedem os homens de cumprirem suas obrigações morais perante o grupo familiar (DUARTE, 1987).

No contexto cultural considerado, as repercussões familiares dos conflitos conjugais ganham relevo nas narrativas femininas: a reprodução doméstica ameaçada, filhos "traumatizados", "revoltados" ou com dificuldades no desempenho escolar, a rotina de trabalho prejudicada, além de tentativas, sem êxito, de obtenção de um emprego. $\mathrm{O}$ fato de não existir uma valoração diferencial das agressões ou ameaças sofridas, geralmente submetidas a um vasto elenco de outras queixas decorrentes do rompimento da reciprocidade conjugal, remete-nos à preeminência do grupo familiar em relação à posição da mulher.

\section{A percepção feminina da violência conjugal}

Nas narrativas femininas dos conflitos conjugais, a categoria "violência" aparece poucas vezes citada. As categorias nativas que identificam os atos agressivos dos parceiros são "ignorâncias", "graças" ou "gracinhas", e o modo deles as perturbarem são "encarnar" ou "encarnação", "ficar infernizando", "botar pilha", no sentido de deixá-las "esquentadas", provocando-lhes "irritação". Tudo se passa como se uma "perturbação" externa ao corpo "encarnasse", mediada por estímulos que podem ser desencadeados pela própria pessoa (aborrecimentos, ingestão de bebida ou droga, por exemplo), pela relação interpessoal ou pela relação com o sobrenatural. O corpo se movimentaria, então, como resposta automática a tais "perturbações". Em seu trabalho, Duarte (1986) comenta sobre a importância de "botar para fora" o excesso de "nervoso", destacando o reconhecimento popular do caráter positivo das brigas e bate-bocas.

A maioria dos relatos contém inúmeras referências às investidas femininas em direção ao homem, como reação ou mesmo como desencadeadoras das agressões sofridas. As entrevistadas narram, naturalizando, os constantes bate-bocas, empurrões, tapas, aperto de braço, sacudidas, mordidas, arranhões que pautam suas relações com os parceiros. Tal quadro era descrito 
também entre consangüíneos e afins, com freqüentes agressões entre marido e mulher, pai e filhos(as), irmão e irmã.

No contexto investigado, os ressentimentos femininos advêm sobremodo do comprometimento da sua reputação moral, segundo a posição que ocupam no meio familiar. Identificando-se com os atributos femininos de "caseira", que "anda na linha direitinha", "boa dona de casa", "menina de família", não é "de rua, de baile", "garota decente", que não dá "margens a desconfianças", "tem mais pudor", as vítimas consideram injustos os sofrimentos provocados pelos parceiros, sobretudo porque vinham cumprindo as obrigações femininas, em particular em seus papéis de esposa e mãe. Além de se considerarem mulheres "direitas", insistem em se distinguir de outras mulheres, com as quais os namorados, companheiros ou maridos também se relacionam, criticando outras parentas mulheres que não se comportam segundo os padrões da honra familiar.

Por sua vez, os homens com os quais convivem (ou conviviam) são avaliados em relação ao padrão ideal: homem provedor com autoridade moral perante a família. Ora eles se encontram aquém deste tipo ideal, sendo "acomodados", "irresponsáveis", "acriançados", como expressa uma informante: "não amadureceu ainda pra criar uma família...". Neste caso, os homens estariam agindo como se fossem ainda solteiros, não arcando com as responsabilidades inerentes ao estatuto de homem casado. Ora estão além do tipo ideal considerado, porque apresentam certas características masculinas de maneira exacerbada, a exemplo de quando são qualificados como trabalhadores, chefes de família, bons pais, mas com "gênio muito forte" ou "nervoso", "atacado", "muito ciumento". Não dormir fora de casa e entregar o dinheiro que ganham para a esposa administrar as despesas domésticas tendem a ser alguns parâmetros da avaliação positiva feminina.

Tendo em vista tal inadequação masculina, o recurso à polícia se impõe como meio de promover o "reajustamento" do parceiro à expectativa social predominante nas camadas populares. Desse modo, a ida à polícia pode significar a manipulação de códigos de reforço da lógica de gênero em pelo menos dois sentidos. No primeiro, as mulheres solicitam um limite ao exercício da dominação masculina, através da interferência de uma "ordem masculina" superior - a polícia. Tal como coloca uma entrevistada, o companheiro não seria "tão macho" diante da polícia. Reconhecendo a legitimidade do poder, entendido enquanto exercício da força, ao gênero masculino, tais mulheres apelam à polícia ou aos traficantes do local onde residem, no intuito de submeterem o parceiro a uma 
"força masculina" superior. No segundo sentido, as mulheres solicitam o restabelecimento do regime ideal de relação entre os gêneros, sem os excessos que o prejudicam.

\section{A vitimização relativizada}

Embora tenham recorrido à DEAM como vítimas, a maioria das entrevistadas atenua tal posição. De um lado, algumas mulheres concebem relacionalmente os conflitos conjugais, não abordando unilateralmente as atitudes agressivas do parceiro, reconhecendo em várias passagens participação na briga que desencadeou o registro ou mencionando atitudes que sugerem certa "guerra conjugal". Determinadas "armas" femininas foram explicitadas: provocá-lo, xingando-o de "corno" ou fazer "greve de tudo" (tarefas domésticas e sexo). De outro, aparecem tentativas de negação ou rompimento com uma imagem de subordinação feminina. As mulheres se apresentam como fortes, independentes financeiramente, que prescindiriam do marido caso ele fosse embora.

Não se trata de menosprezar o sofrimento causado por relações desiguais de poder para quem ocupa posição inferior na hierarquia conjugal. Relativizar a vitimização não significa desconhecer a eventual brutalidade das situações nas quais as mulheres estão envolvidas. No entanto, não se pode tratar linearmente o discurso feminino que contempla a vitimização, pois ele tem uma dinâmica interna própria (GREGORI, 1992). Uma permanente tensão perpassa o estabelecimento das conjunções que ordenam a relação entre os gêneros, passíveis de mudança segundo a forma como reagem.

Concomitantemente às "perturbações" masculinas, as entrevistadas se orgulham de possuir atributos positivos, que os parceiros não detêm: maior responsabilidade perante a família, quando assumem seu sustento, menor susceptibilidade às influências maléficas de terceiros (amigos, irmãos ou outras mulheres que os conduzem às drogas e à bebida). São, portanto, mais fortes e resistentes (moralmente) até mesmo para não sucumbirem às "macumbas" das sogras, que recaem sobre os "fracos" companheiros. Ao que parece, nas representações femininas, os homens são "fracos" porque se deixam mais facilmente ser "levados" ou "influenciados" pelos outros.

Em resumo, o lugar de vítima (simbolizado pelo registro na DEAM) é acionado para reordenar os parâmetros que mantêm a conjugalidade sob constante tensão, introduzindo um elemento inusitado, pelo menos na expectativa 
da maioria dos parceiros. Trata-se de uma mudança brusca no comportamento feminino. Até então as mulheres procuravam resolver tais problemas no âmbito do grupo de parentesco e vizinhança, ou mediante o recurso a diversas igrejas. Em tese, a partir do registro na DEAM, elas passam a delegar à autoridade policial a tarefa de corrigi-los. Sem dúvida alguma, esse fato altera substancialmente a correlação de forças no casal, sendo, no entanto, diferentes os resultados práticos obtidos.

\section{O atendimento policial na DEAM}

A resposta policial à demanda recebida na DEAM termina por transformar a "suspensão" da queixa em mais um procedimento de rotina na delegacia. Freqüentemente os policiais discordam que a solução penal seja o caminho mais indicado para o enfrentamento social da maioria das denúncias feitas à DEAM. A despeito de suas atribuições legais, o recurso à polícia pode ser interpretado como mais um "problema" para a vítima ou como uma resposta pouco eficaz às suas queixas.

Dois elementos recorrentes no discurso policial evidenciam as balizas da atividade policial na DEAM. De um lado, a postura de hesitação da vítima quanto à possibilidade de incriminar o parceiro acusado. Este argumento é reforçado pela constatação de que muitas mulheres não retornam à delegacia após o registro e outras comparecem espontaneamente para "retirar" a queixa ou concordam com sua "suspensão", quando sugerida pela(o) policial responsável. De outro lado, a ineficácia do sistema judicial, no tocante à punibilidade dos acusados (CARRARA et al., 2002). Ouve-se com frequiência na DEAM: "Não vai dar em nada!" Premida entre tais constatações, a ação policial tem seu sentido questionado e a própria delegacia chega a ser alvo de debate.

A desqualificação da vítima e a banalização dos conflitos são traços marcantes nas conversas de bastidores da DEAM. As mulheres são designadas pela(o)s policiais como "gentinha", "mocréias", "mentirosas", "malas", "retardadas", "desequilibradas", "donas". Os conflitos apurados são qualificados como "baixaria", "putaria", "briga de comadre", "fofocas", "circo", "feijoada", "coisa de gente à toa". Em geral, os homens acusados não são considerados "bandidos", ao contrário, por exemplo, dos estupradores, que despertam a repulsa policial.

Com raras exceções, parece ser difícil para a(o)s policiais compreenderem a complexidade do processo no qual estão mergulhadas as 
mulheres que convivem com a violência conjugal. Ela(e)s desqualificam a vítima que decidiu interromper as investigações, classificando-as em dois grupos: as "sem-vergonha" - "é tudo descaração", "dão moleza pros caras", "as que merecem", "gostam de apanhar", como sugere o comentário policial: "Taí, apanha mas engravida do cara; 99,9\% são assim"- e as "pobres coitadas", cuja "passividade" seria atribuída à submissão feminina decorrente de sua dependência emocional e material aos homens, o que excluiria a opção de penalizá-los.

A burocratização do trabalho de investigação deixa os policiais imersos numa rotina de trabalho, com prazos e tarefas a cumprir, tornando-os pouco disponíveis para uma intervenção mediadora. Oscilam entre cumprir suas atribuições legais e a necessidade de uma abordagem não estritamente policial, mas "social" ou "psicológica", para a qual não se sentem preparados. Dentre as diversas atividades policiais, consideram a abordagem de relações domésticas menos relevante. No intuito de racionalizar o trabalho decorrente de expressiva demanda frente à escassez completa de recursos para operacionalizá-lo, acabam por naturalizar a violência conjugal e banalizar a intervenção sobre a mesma.

Neste sentido, costumam incentivar as mulheres a desistirem do inquérito, mediante a interposição de aspectos que dificultariam uma provável condenação do acusado. Junto à questão central colocada à vítima ("vai prosseguir ou não?"), desenrolam-se dois argumentos “técnicos", remetidos à probabilidade de aquele inquérito ser aceito pelo promotor, que ofereceria então a denúncia ao juiz. São eles: a ausência de testemunha nos crimes de ameaça e a não-gravidade da lesão, atestada pelo IML, nos crimes de lesão corporal. Como boa parte das ameaças ocorre em espaço privado, na ausência de outras pessoas, e quase a totalidade dos laudos do IML indica lesões "leves", as vítimas, em sua maioria, são aconselhadas a evitar um "inquérito capenga".

Seja porque o prazo para concluir a investigação está se esgotando, porque o suspeito se encontra em local desconhecido, dificultando o envio do convite ao mesmo, ou porque prováveis testemunhas ou informantes sejam parentes dos envolvidos, nem sempre aceitos pela(o)s policiais, um registro de ameaça sem a devida apresentação de testemunhas acaba sendo um "forte candidato" à suspensão. Paradoxalmente, se considerarmos que 88\% das acusações de ameaça foram arquivadas em duas Centrais de Inquérito do estado, no período entre 1991 e 1995, segundo Carrara et al. (2002), tal conduta policial estaria, de certa forma, apenas antecipando um "provável arquivamento". 
No crime de lesão corporal, a materialidade é fornecida pelo Auto de Exame de Corpo de Delito, realizado pelo IML. Mediante tal documentação $\mathrm{a}(\mathrm{o}) \mathrm{s}$ policiais avaliam a quantidade, o tipo ou tamanho das lesões encontradas, sua distribuição pelo corpo (se cobrem diferentes regiões do corpo ou apenas um membro, se atingem partes mais ou menos "nobres" - cabeça versus pernas, braços), bem como os quesitos que informam sobre a gravidade da lesão, tomando seu caráter "leve", como uma possível fragilidade do inquérito que não passaria despercebida pelas autoridades competentes. Conforme Carrara et al. (2002), no período de 1991 a 1995, apenas 54\% das acusações de lesão corporal foram denunciadas pela promotoria na primeira Central de Inquérito e $25 \%$ na segunda.

Além desses argumentos, a(o)s policiais costumam invocar os prejuízos que um inquérito desencadearia ao acusado e sua família, sondar sobre a interrupção das agressões ou ameaças, ou sobre a atual situação conjugal do casal, tomando tanto a reconciliação quanto a separação como sinais de que os problemas vêm sendo superados ou encaminhados. Em síntese, o ato de a vítima representar ou não contra o parceiro (ou ex-parceiro) polariza muito mais o interrogatório policial do que propriamente a violência cometida pelo acusado. ${ }^{4} \mathrm{O}$ investimento na apuração rigorosa do fato denunciado cede lugar à discussão sobre a conduta moral da vítima e do acusado, sobre o cumprimento das obrigações domésticas pertinentes aos homens e às mulheres, sobre a necessária disponibilidade da vítima para comparecer às instâncias competentes em todas as fases seguintes - enfim, sobre as consequiências que podem atingi-la mediante a "ira" do suspeito.

É compreensível que as mulheres não criminalizem o comportamento de seus parceiros, pelo vínculo familiar que os une. Decerto a maioria dos suspeitos não possui uma carreira no mundo do crime. No entanto, tal avaliação não pode anular a atuação da polícia, deixando a vítima à mercê da sorte, nos casos que exigem intervenção mais efetiva. As críticas de duas informantes traduzem bem a insatisfação com a DEAM. Dizendo que a delegacia "chama sempre a vítima", enquanto o acusado, que deveria ser chamado, "fica no seu canto", uma delas retruca: "Quem sempre é convocado a depor é a vítima e o suspeito nem é incomodado. Quem apanha é quem tem que dar explicação?”. Outra expressa: "Eu esperava mais da delegacia de mulheres [...]. O criminoso sempre nega. Se eu faço a denúncia, sou eu que tenho que comprovar?”.

A cada "suspensão", o discurso policial que anuncia "são todas iguais" e "sempre voltam atrás" é então reforçado. Trata-se de um jogo perverso, pois se há uma crítica enfática à atitude da vítima que se posiciona espontaneamente 
favorável à "suspensão" da queixa, destituindo-a de credibilidade e generalizando sua conduta às demais mulheres que acionam a DEAM, tal crítica convive com mecanismos mais ou menos sutis que orientam outras para o mesmo caminho.

\section{A "suspensão" da queixa policial sob a ótica feminina}

Os desdobramentos decorrentes da denúncia que conduzem a mulher à "suspensão" da queixa registrada na DEAM sugerem a resolução ou o encaminhamento total ou parcial da crise conjugal, seja pela via da reordenação do contexto familiar, na tentativa de readequá-lo aos padrões morais valorizados ou pela negociação da separação conjugal.

A forma como as mulheres concebem a "suspensão" da queixa policial é importante. Elas não a reconhecem como um ato contraditório à denúncia, conforme a lógica jurídico-policial, uma resposta fracassada (porque os trâmites legais teriam sido interrompidos) ou mesmo uma renúncia a um direito, no sentido de que teriam sucumbido ou desistido de reagir às investidas violentas masculinas. Ao contrário, atribuem-lhe um sentido positivo que indica certo êxito na negociação com o parceiro ou ex-parceiro acusado, seja em relação ao objetivo de reordenação do contexto familiar ou de viabilização da separação conjugal. Em alguns casos, também encontramos a suspensão ligada a um mal-estar da vítima com a denúncia realizada, por ter sido uma decisão precipitada ou não suficientemente planejada.

Os argumentos que justificam a "suspensão" novamente se referem à preocupação com os filhos, à reinterpretação do conflito ocorrido e finalmente à necessidade de preservação da moradia da família, dada a importância material e simbólica que a casa adquire no contexto analisado. Três modos de reelaboração do conflito foram identificados.

O primeiro encerra uma reavaliação da atitude agressiva do parceiro, irresponsabilizando-o, devido à sua fragilidade "natural", que o torna "doente", "nervoso", "alcoólatra", "viciado". Ao contrário do discurso feminino subjacente aos registros, a agressividade do companheiro é agora inserida num contexto em que a vulnerabilidade masculina ganha destaque. ${ }^{5} \mathrm{Se}$, por um lado, reconhecem que o gênero masculino detém maior força física, relativizam tal qualidade do parceiro com uma fraqueza "moral" que o teria acometido, tornando-o suscetível a inúmeras "perturbações" de ordem "físico-moral". O comportamento do companheiro é, então, atribuído a um estado doentio, vinculado 
ao uso de bebida alcoólica ou drogas, sendo passível de tratamento médico (psiquiátrico) ou psicológico, e não policial. Constatando certo comprometimento (avaliado como debilidade) na totalidade do comportamento masculino, as mulheres justificam dessa forma o conflito ocorrido.

O segundo modo implica uma leitura mágico-espiritual do conflito, atribuindo-o a uma interferência de ordem sobrenatural, o que também alivia a responsabilidade masculina. As categorias "virou a cabeça", "endemoniado", "um espírito ruim que tá nele", "parecia que tava com o diabo no corpo" ilustram a situação. Assim, elas atribuem as atitudes agressivas dos parceiros a uma ordem sobrenatural, perante a qual estes sucumbem. Tanto quanto o "nervoso" e suas variações, essa interferência suprapessoal responde por muitas das "perturbações" masculinas (abandono de emprego, bebida, ciúmes, "más companhias", outras mulheres, confusão com os vizinhos, não repasse do dinheiro à família, gastandoo todo consigo), além dos maus-tratos sofridos. Nas duas situações acima, a via religiosa também surge como outro recurso tradicionalmente invocado para a superação do conflito e para a reordenação familiar.

Não concebendo as atitudes desaprovadas no parceiro como resultado de seu livre-arbítrio ou determinação individual, as mudanças ocorridas no comportamento masculino são então explicadas no contexto de uma instância suprapessoal. A adesão ao discurso religioso é expressiva dessa lógica cultural das camadas populares na qual a pessoa não pode ser entendida dentro dos marcos de responsabilização presentes no ideário individualista.

A terceira modalidade de reconstrução dos fatos inclui uma reavaliação da própria participação no conflito, quando a vítima assume parcela da responsabilidade frente ao ocorrido. Algumas chegam também a minimizar seu registro frente aos demais, atenuando a gravidade da violência sofrida, na tentativa de se distinguirem da maioria das mulheres que freqüentam a DEAM. Paradoxalmente, frente à expectativa feminista de consolidar uma identidade coletiva erigida sobre uma experiência comum, tais mulheres insistem em sublinhar a excepcionalidade de sua demanda à DEAM, recusando seu pertencimento àquele contex to ou diferenciando-se da imagem de vítimas que atribuem às outras mulheres.

Em suma, todos esses elementos são componentes fundamentais de uma cosmovisão, onde as "perturbações" (incluindo a violência do parceiro) têm estatuto "físico-moral", sendo valorizadas, explicadas e enfrentadas a partir de referências centrais a tal concepção - a saber, a posição no grupo familiar, a 
sociabilidade local (a casa representa uma forma de garantir a inserção na rede de parentesco e de vizinhança) e as crenças religiosas compartilhadas. As noções de responsabilidade e direito são sempre levantadas com conotação relacional, submetidas à reciprocidade, à complementaridade e hierarquia que ordenam o grupo familiar e não sob a perspectiva individualista.

Dois aspectos freqüentemente relacionados com a intenção da vítima em "retirar" a queixa, corroborados pelo discurso policial e pelo senso comum, precisam ser considerados. O primeiro vincula a "suspensão" à dependência econômica da vítima. ${ }^{6}$ Não descartamos que dificuldades materiais as impelem a ponderar sobre uma possível separação, mas generalizar tal argumento para explicar a opção feminina de persistir na companhia do parceiro agressor seria subestimar sua capacidade de reagir, de encontrar resposta dentre os recursos que dispõe. No cotidiano da delegacia, muitas mulheres que optaram ou concordaram com a "suspensão" da queixa declaravam exercer uma atividade remunerada mais estável do que os companheiros (em geral, biscateiros, desempregados).

O segundo supõe que as vítimas que "suspendem" a queixa geralmente o fazem porque se reconciliaram com seus parceiros, utilizando tal argumento para questionar a legitimidade da maioria das denúncias recebidas pela DEAM. Como vimos, esse recurso é utilizado por vítimas que também se decidiram pela ruptura do laço conjugal, podendo constituir mais um elemento na negociação da separação com o parceiro. Dentre as informantes, 15 vítimas se reconciliaram com os parceiros e 16 manifestaram-se pela separação.

De todo modo, o recurso à polícia tem uma função específica interromper momentaneamente aquele ciclo de violência, introduzindo, através do registro na DEAM uma autoridade que contribuiria para modificar a correlação de forças no contexto familiar - e uma vigência também específica, porque impediria que a negociação entre os parceiros se restabelecesse. O desfecho pode vir a ser o rearranjo das relações conjugais e familiares, a saída do acusado ou da própria vítima de casa, ou outro acordo informal que possibilite a separação. Mesmo havendo o encaminhamento legal da separação (que já havia sido desencadeado ou está por se iniciar), esta opção também exclui o tratamento penal do fato denunciado.

Os resultados obtidos na investigação sugerem que as mulheres das classes trabalhadoras utilizam a DEAM preponderantemente como um recurso simbólico, coerente com o ideário que compartilham e as condições sociais em que vivem. 


\section{A DEAM como um recurso simbólico}

A maioria das mulheres que se dirige à DEAM não tem suas expectativas atendidas, pois nem sempre encontram policiais disposta(o)s a exercer a função de mediadores em suas contendas domésticas. Por que então continuam recorrendo insistentemente à DEAM? Argumenta-se que os efeitos produzidos pela queixa policial no contexto familiar da vítima advêm prioritariamente da utilização da delegacia como um recurso simbólico (LÉVISTRAUSS 1975a, 1975b).

Decerto há expectativa feminina de uma mediação policial imediata e eficaz junto ao acusado, na direção da "renegociação dos pactos domésticos", como apontam alguns autores (SOARES et al., 1996; SOARES, 1996; MUNIZ, 1996). No entanto, o volume da demanda que a DEAM recebe, a conseqüente burocratização das atividades policiais, aliada à generalizada insatisfação policial com o trabalho que ali desenvolvem, tornam a(o)s policiais pouco disponíveis para uma atuação neste sentido. Ainda assim, é significativo que sua precária eficácia prática não seja um problema para as usuárias. De fato, os efeitos obtidos com a queixa policial não são decorrentes da intervenção direta (punitiva ou mediadora) da autoridade policial no conflito denunciado. O encaminhamento das questões que redundaram em ameaças ou agressões físicas não está necessariamente vinculado ao espaço da delegacia.

Tal negociação se faz efetivamente entre a própria vítima e o acusado, no âmbito privado, mediante a influência indireta da DEAM. A faceta preponderante na relação que as mulheres estabelecem com o aparato policial está condensada na possibilidade de acionarem a imagem da polícia como um recurso, concomitantemente, de autoproteção e de repreensão da conduta dos parceiros. Tal aspecto garante à DEAM um lugar fundamental nas representações femininas, que a reconhecem como uma delegacia de defesa dos seus interesses. Sendo assim, a queixa policial já representa em si uma tentativa de ruptura com uma dada configuração do contexto conjugal ou familiar e com determinada autoimagem da mulher. Através da DEAM, ganham-se forças para retomar a negociação conjugal, agora em posição privilegiada. A queixa policial efetuaria, assim, um deslocamento simbólico na posição de cada elemento do par conjugal, invertendo momentaneamente a relação assimétrica entre os gêneros. Um exemplo pode ser dado: uma vítima reproduziu cópias da convocação policial ao acusado (ex-marido), remetendo-as ao síndico do prédio onde ele morava e à diretoria da empresa na qual trabalhava, submetendo-o a extremo constrangimento público. 
Com interesses diversos, seja para facilitar o acordo sobre a separação conjugal ou para corrigir distorções ou desvios que ameaçam o grupo familiar (decorrentes das "perturbações" masculinas), no intuito de sua preservação, as mulheres procuram instaurar nova base para a interação, instituindo um novo patamar de discussão e negociação conjugal, que conduzem independentemente da atuação direta da polícia. No levantamento das queixas "suspensas" em $1995,48,82 \%$ dos acusados nem chegaram a comparecer à DEAM. Dentre as entrevistadas, 13 acusados também não atenderam aos convites da DEAM.

Sendo os convites entregues ou não pelas vítimas aos acusados, eles comparecerem ou não à DEAM, há efeitos produzidos pelo recurso policial. Eles são obtidos devido às mudanças desencadeadas pela queixa no comportamento de boa parte dos homens e na representação que os mesmos tinham de suas parceiras. A forma peculiar que as mulheres encontram para lidar com a polícia as faz administrar todas as etapas do registro em proveito próprio, já que passam a demonstrar para a família algum controle do processo policial, deixando o parceiro acuado. Essa atitude evidencia um certo cálculo, no sentido de maximizarem os benefícios ou vantagens que podem obter com a denúncia policial. Assim, a entrega do convite ao acusado, a expectativa dos depoimentos e do resultado da "perícia", a recusa do acusado em comparecer à DEAM, a decisão de instaurar ou não o inquérito são tomados como momentos propícios para se fomentar a hipótese de punição do agressor.

Aguardando a convocação policial ou escolhendo o momento que melhor lhes convém, a "suspensão" da queixa finalmente se coloca como um trunfo. Se a vítima "deixar correr" ou "der andamento", o parceiro pode vir a ser preso. Muitas mulheres admitem ainda que não vão contar aos companheiros sobre a "suspensão", deixando-os na dúvida quanto ao encaminhamento dado. Trata-se de mais uma tentativa feminina de se manter em posição senão mais favorável, no mínimo, menos vulnerável a novas ameaças ou agressões.

Durante o intervalo de tempo entre a queixa e sua "suspensão" (ou seu conhecimento pelo parceiro), elas passam a ter, pelo menos simbolicamente, o futuro do companheiro em suas mãos, pela virtualidade de uma medida penal, mesmo que eles duvidem de uma punição ou desprezem a ação policial. Para elas, esse efeito perdura além da "suspensão" da queixa, porque, na iminência de novas agressões, advertem com a possibilidade de voltarem à DEAM, o que agravaria a situação do parceiro, caso fosse novamente denunciado. 
Mediante tal contexto, a decisão feminina de "suspensão" da queixa policial adquire um sentido próprio, estando inserida numa lógica específica que a vincula aos desdobramentos ocorridos após o registro na DEAM. A "suspensão" da queixa é mais um elemento de negociação de que a vítima disporia para barganhar com o acusado, no sentido de que ele interrompa as agressões e volte a cumprir as obrigações masculinas assumidas ou, no mínimo, não a perturbe mais. Em suma, sem abrir mão de seus valores, as mulheres recorrem estrategicamente à ordem legal, mas não delegam total e incondicionalmente à DEAM a resolução de sua crise conjugal ou familiar, procurando gerenciá-la paralelamente à ação policial. Embora não compartilhem da concepção de cidadania que preside as demandas jurídico-policiais (DUARTE et al., 1993), elas possuem um modo peculiar de "lutarem" pelo que consideram ser "seus direitos" (BRANDÃO, 2004).

A análise desenvolvida não descreve a totalidade dos casos observados na delegacia, mas uma tendência dominante na relação que tais mulheres estabelecem com o aparato policial. Além da DEAM, uma série de outros recursos pode ser acionada para enfrentar tais situações adversas: igrejas, Defensoria Pública, parentes, líderes do tráfico e, em casos raros, a própria força física -"Eu quebrei ele na porrada. Agora tá uma seda".

A princípio, essa postura colide com a concepção de cidadania que se espera daqueles que acionam a polícia. No entanto, não se considera que as mulheres prescindam da DEAM ou que ela seja dispensável. Mesmo imersas em relações conjugais violentas, moldadas num contexto familiar hierárquico e assimétrico, em que tradicionalmente o gênero feminino ocupa posição subordinada ao masculino, as mulheres não esboçam uma existência marcada exclusivamente pela desventura. Ao contrário, buscam gerir as crises conjugais, negociar soluções, mobilizando os recursos que consideram importantes para encaminhar respostas ao conflito.

\section{Considerações finais}

O entrelaçamento entre ordem familiar e efetivação da cidadania feminina permanece sendo uma tensão no encaminhamento de soluções ao problema da violência contra a mulher. Nem sempre tais lógicas são coincidentes ou se combinam a um bom termo. Penetrar nas representações e práticas das mulheres permite captar continuidades e descontinuidades na trajetória de 
enfrentamento feminino da violência marital. Mesmo que elas concebam sua existência social subordinada às regras do grupo familiar, não se posicionando como indivíduos autônomos, elas estão freqüentemente em interação com o imaginário que prescreve a individualização dos sujeitos sociais, através da mídia, do contato com mulheres de outras classes sociais, dos discursos de especialistas do Direito, da Psicologia, de feministas, dentre outros. Elas estão expostas ao que Debert $(2002$, p. 7) discute como "judicialização das relações sociais e afetivas", sendo atingidas pelos discursos jurídicos, mediante contatos com advogados e instituições do sistema judiciário, pela crescente penetração do Direito na organização da vida social. Muitas delas conseguem perceber as fraturas desse modelo ideal familiar em razão do fracasso do desempenho do parceiro, desconstruindo o mito da harmonia familiar. Ainda assim, os direitos por elas reivindicados não se coadunam plenamente à lógica universalizante que engendra a cidadania.

O problema reside no fato de que nem as DEAMs nem os JECRIMs podem atuar com base na restauração de um modelo familiar ideal, supondo uma incapacidade ou fragilidade de seus integrantes, tomados como incompetentes para a vida conjugal, "cidadãos falhos" na ótica da justiça, incapazes de gerir a própria vida, na acepção de Debert (2002). Tal como expressam Debert (2002) e Debert e Oliveira (2005), se o imperativo da vida familiar fundamentar as práticas sociais de policiais ou operadores do direito, há o risco de se reprivatizar uma questão pública, reduzindo-se a importância política das DEAMs, um legado feminista que conferiu visibilidade social à violência contra a mulher.

\section{Referências}

AZEVEDO, Carla A. L. S. Mulher gosta de apanhar? Violência contra a mulher e condicionantes jurídicos. 2005. 25p. Mimeografado.

BRANDÃO, Elaine R. Nos corredores de uma Delegacia da Mulher: um estudo etnográfico sobre as mulheres e a violência conjugal. 1997. 202p. Dissertação (Mestrado em Saúde Coletiva) - Instituto de Medicina Social, Universidade do Estado do Rio de Janeiro, Rio de Janeiro, 1997.

. Violência conjugal e o recurso feminino à polícia. In: BRUSCHINI, C., HOLLANDA, H. B. (Orgs.). Horizontes plurais: novos estudos de gênero no Brasil. São Paulo: Ed. 34, 1998. p. 51-84. 
"Eu quero saber quais são os meus direitos": a complexa trama entre cidadania e lógica familiar. In: STREY, M. N., AZAMBUJA, M. P. R., JAEGER, F. P. (Orgs.). Violência, gênero e políticas públicas. Porto Alegre: EDIPUCRS, 2004. p. 85-99.

CARRARA, S., VIANNA, A. R. B., ENNE, A. L. "Crimes de bagatela": a violência contra a mulher na Justiça do Rio de Janeiro. In: CORREAA, M. (Org.). Gênero e cidadania. Campinas: Pagu/UNICAMP, 2002. p. 71-106.

DEBERT, Guita. G. Arenas de conflitos éticos nas Delegacias Especiais de Polícia. Primeira Versão. Campinas: IFCH/UNICAMP, n. 114, 2002. 49p. Mimeografado.

DEBERT, G. G., BERALDO OLIVEIRA, M. Os modelos conciliatórios de solução de conflitos e a violência doméstica. 2005. 26p. Mimeografado.

DUARTE, Luiz F. D. Da vida nervosa nas classes trabalhadoras urbanas. Rio de Janeiro: Jorge Zahar, 1986. 290p.

. Pouca vergonha, muita vergonha: sexo e moralidade entre as classes trabalhadoras urbanas. In: LOPES, J. S. L. (Org.). Cultura e identidade operária: aspectos da cultura da classe trabalhadora. Rio de Janeiro: Marco Zero, 1987. p. 203-226.

DUARTE, Luiz F. D. et al. Vicissitudes e limites da conversão à cidadania nas classes populares brasileiras. Revista Brasileira de Ciências Sociais, São Paulo, n. 22, p. 5-19, jun. 1993.

GREGORI, Maria F. Cenas e queixas: um estudo sobre mulheres, relações violentas e a prática feminista. Rio de Janeiro: Paz e Terra, 1992. 218p.

GROSSI, Miriam P. Rimando amor e dor: reflexões sobre a violência no vínculo afetivo conjugal. In: PEDRO, J. M., GROSSI, M. P. (Orgs.). Masculino, feminino, plural: gênero na interdisciplinaridade. Florianópolis: Ed. Mulheres, 1998. p. 293-313.

HEILBORN, Maria L. Gênero e hierarquia: a costela de Adão revisitada. Estudos Feministas, Rio de Janeiro, v. 1, n. 1, p. 50-82, 1993.

IZUMINO, Wânia P. Delegacias de Defesa da Mulher e Juizados Especiais Criminais: mulheres, violência e acesso à justiça. In: XXVIII Encontro da ANPOCS. Caxambu, 2004. 25p. 
KANT DE LIMA, R. A polícia da cidade do Rio de Janeiro: seus dilemas e paradoxos. Rio de Janeiro: Polícia Militar do Estado do Rio de Janeiro, 1994.

KNAUTH, Daniela R. Evitando a morte masculina: a perspectiva das mulheres dos homens portadores do vírus da AIDS. In: XIX Encontro da ANPOCS. Caxambu, 1995.

LÉVI-STRAUSS, C. A eficácia simbólica. In: Antropologia estrutural. Rio de Janeiro: Tempo Brasileiro, 1975a. p. 215-236.

O feiticeiro e sua magia. In: Antropologia estrutural. Rio de Janeiro: Tempo Brasileiro, 1975b. p. 193-213.

MOTA, P. P. A polícia e os pobres: representações sociais e práticas em delegacias de polícia do Rio de Janeiro. 1995. Dissertação (Mestrado em Serviço Social) - Escola de Serviço Social, Universidade Federal do Rio de Janeiro, Rio de Janeiro, 1995.

MUNIZ, Jaqueline Os direitos dos outros e outros direitos: um estudo sobre negociação de conflitos nas DEAMs/RJ. In: SOARES, L. E. (Org.). Violência e política no Rio de Janeiro. Rio de Janeiro: Relume Dumará, 1996. p. 125164.

SALEM, Tânia. Mulheres faveladas: "com a venda nos olhos". In: FRANCHETTO, B. et al. (Orgs.). Perspectivas Antropológicas da Mulher. n. 1. Rio de Janeiro: Zahar, 1981. p. 49-99.

SANTOS, M. C. MacDowell. Gender under Construction by/in the State: the Case of the Women's Police Stations. Berkeley: University of California, 1996. Mimeografado.

- Delegacias da Mulher em São Paulo: percursos e percalços.

Disponível em: http://copodeleite.rits.org.br/apc-aa-patriciagalvao/home/ noticias.shtml? $\mathrm{x}=189$. Acessado em: 30 mai 2006.

SARTI, Cynthia A. Reciprocidade e hierarquia: relações de gênero na periferia de São Paulo. Cadernos de Pesquisa, São Paulo, n. 70, p. 38-46, agosto 1989.

A família como espelho: um estudo sobre a moral dos pobres. Campinas: FAPESP, 1996. 128p.

SOARES, Bárbara M. Delegacia de atendimento à mulher: questão de gênero, número e grau. In: SOARES, L. E. (Org.). Violência e política no Rio de Janeiro. Rio de Janeiro: Relume Dumará, 1996. p. 107-123. 
SOARES, L. E. et al. Violência contra a mulher: as DEAMs e os pactos domésticos. In: SOARES, L. E. (Org.). Violência e política no Rio de Janeiro. Rio de Janeiro: Relume Dumará, 1996. p. 65-105.

\section{NOTAS}

- Doutora em Saúde Coletiva, IMS-UERJ (2003); professora adjunta no Departamento de Medicina Preventiva da Faculdade de Medicina e no Núcleo de Estudos de Saúde Coletiva, Universidade Federal do Rio de Janeiro. Endereços eletrônicos: elainerb@uol.com.br e brandao@nesc.ufrj.br

${ }^{1}$ A Lei n ${ }^{\circ}$ 9.099/95 cria os Juizados Especiais Criminais, com "competência para a conciliação, o julgamento e a execução das infrações penais de menor potencial ofensivo", ou seja, com pena máxima até um ano, introduzindo a exigência de representação do ofendido para a ação penal relativa aos crimes de lesões corporais leves e lesões culposas.

${ }^{2}$ Uma versão mais ampla do texto foi publicada em Brandão (1998). A investigação teve apoio do II Programa Relações de Gênero na Sociedade Brasileira, da Fundação Carlos Chagas/ Fundação Ford.

${ }^{3}$ Quanto ao perfil socioeconômico das entrevistadas, a maioria (25) possuía idade entre 20 e 40 anos, cinco tinham mais de 40; uma, 15; 14 eram cariocas e o restante das regiões Nordeste e Norte, Sudeste e Centro-Oeste; 15 tinham primeiro grau incompleto; oito, primeiro grau completo; três, segundo grau completo; uma, curso superior, não exercendo a profissão de pedagoga e uma fazia pré-vestibular. Não há informações sobre as quatro restantes. Quanto à ocupação, 12 não exerciam atividade remunerada. Do restante, sete eram empregadas domésticas, quatro eram comerciárias, duas faziam serviços administrativos, duas eram vendedoras autônomas (de pipoca, produtos de beleza) e as demais: bancária, securitária, camareira de hotel, auxiliar operacional em maternidade e organizadora de passeios turísticos. O tempo de relacionamento com o parceiro acusado varia entre até cinco anos (12), de 6 a 10 anos (9), de 11 até 20 anos (9) e duas com mais de 20 anos de união. Dentre elas, 25 têm filhos (quatro de relacionamentos anteriores), seis não os possuíam e uma encontrava-se grávida. Sete acusados estavam desempregados e sobre quatro não dispomos de informações; 21 exerciam atividades remuneradas que variavam entre motorista ou cobrador de ônibus, mecânico, garçom, vigilante, chaveiro, militar, etc. 
${ }^{4} \mathrm{O}$ foco no (não-)prosseguimento, por parte da mulher, de sua acusação, permanece central nas intervenções dos conciliadores que atuam nos JECRIMs (DEBERT, OLIVEIRA, 2005; AZEVEDO, 2005).

${ }^{5}$ Knauth (1995) destaca a vulnerabilidade masculina como justificativa feminina para nãoculpabilização do parceiro e não-ruptura da aliança, quando as mulheres se descobrem infectadas pelo HIV transmitido pelos próprios parceiros.

${ }^{6}$ Das 32 entrevistadas, 12 não exerciam atividade remunerada. Nos registros "suspensos" de 1995, 19,19\% eram "do lar"; 42,65\% exerciam atividades remuneradas e em 38,15\% deles não há informações a respeito. 


\section{Disclaiming of Rights? Public Policies to Tackle Violence against} Women: the Case Study of the Women's Police Station

This paper deals with the "suspension" of complaints from the records of the Women's Police Station, until Act n. 9.099/95. The ethnographic study was carried out at a police station in the state of Rio de Janeiro (1995-1996) and included the examination of police records, interviews with the victims and observation of daily work at the office. Quite often women from the working class who are victims of marital violence chose not to legally punish their partners, contrarily to feminist's expectations. The results show the specificities of the feminine demand to the police, in which denounced crimes are included in a wider ensemble of complaints referred to male "disturbances" to the family order. The "suspension" of the complaint appears in such context as a police procedure which finds support in the doubtful position of the victims as for the criminalization of their partner's attitude and in the probable impunity of the accused, a strong characteristic of the Brazilian juridical system. Since most victims see the police intervention as a way to reorganize the familiar and conjugal relationship or to make it possible for a conjugal separation, they tend to administer its interference to their own benefit, regaining negotiations with the accused in a superior position to the one in which they found themselves before. Seen through the eyes of women, the "suspension" would be not a contradictory act to the denouncement but an element which could favor the return to a lost reciprocity.

Key words: Gender; violence against women; Women's Police Station; family. 